\title{
PEMBUATAN KARBON AKTIF DARI KULIT JERUK KEPROK (Citrus reticulata) UNTUK ADSORBSI PEWARNA REMAZOL BRILLIANT BLUE
}

\author{
Asriningtyas Ajeng Erprihana ${ }^{1}$ dan Dhoni Hartanto ${ }^{2 *}$ \\ 1,2 Prodi Teknik Kimia, Fakultas Teknik, Universitas Negeri Semarang, Jl Raya Sekaran, Gunungpati, Semarang 50229, \\ Indonesia \\ *E-mail penulis: dhoni.hartanto@gmail.com
}

\begin{abstract}
Abstrak
Limbah kulit jeruk keprok (Citrus reticulata) sering dijumpai di industri pembuatan berbagai macam minuman seperti jus, sirup, dan sari buah. Limbah kulit jeruk ini hanya akan dibuang begitu saja dengan jumlah banyak, dan pada akhirnya limbah ini akan mencemari lingkungan. Salah satu upaya peningkatan nilai ekonomis limbah kulit jeruk dapat dilakukan dengan mengolahnya menjadi karbon aktif. Penelitian ini bertujuan untuk menghasilkan karbon aktif dari kulit jeruk keprok dengan aktivasi kimia, luas permukaan, serta mengetahui kemampuannya dalam mengadsorpsi zat warna Remazol Brilliant Blue. Kulit jeruk yang telah dibersihkan dari kotoran, dikeringkan menggunakan oven pada suhu $120^{\circ} \mathrm{C}$ selama 3 jam. Aktivator yang digunakan dalam penelitian ini adalah $\mathrm{H}_{3} \mathrm{PO}_{4}$ dengan rasio massa aktivator : massa karbon 1:1. Aktivasi dilakukan pada temperatur $600^{\circ} \mathrm{C}$ selama $1 \mathrm{jam}$, kulit jeruk kemudian dicuci dengan aquades dan dikeringkan menggunakan oven pada suhu $150^{\circ} \mathrm{C}$ selama 6 jam. Setelah itu, dilakukan uji bilangan iodin terhadap sampel hasil penelitian. Adsorpsi zat warna Remazol Brilliant Blue oleh karbon aktif kulit jeruk dilakukan dengan variasi waktu kontak dan massa karbon aktif untuk mencari kondisi adsorpsi optimum. Kondisi optimum adsorpsi zat warna Remazol Brilliant Blue oleh karbon aktif pada kulit jeruk keprok pada waktu kontak 30 menit dengan massa karbon aktif 1 gram. Karbon aktif dari kulit jeruk keprok memiliki luas permukaan karbon aktif sebesar 529,17 mg/g berdasarkan daya serapnya terhadap larutan iodin.
\end{abstract}

Kata kunci: adsorpsi, bilangan iodin, karbon aktif, kulit jeruk, Remazol Brilliant Blue

\begin{abstract}
Orange peel (Citrus reticulate) waste is often found in industrial manufacturing various kinds of beverages such as juice, syrup, fruit juice. Orange peel waste is just be thrown away with the lot number, and in the end of this waste will pollute the environment. One of the efforts to increase the economic value of orange peel waste by using the process which convert waste into activated carbon. This research aims are to produce activated carbon from orange peel with chemical activation, to determine the surface area, and its ability to adsorb Remazol Brilliant Blue dyes. Orangel peel that have washed, dried in oven at $120^{\circ} \mathrm{C}$ for 3 hours. $\mathrm{H}_{3} \mathrm{PO}_{4}$ is activating agent that used in this research with mass ratio activating agent : mass carbon 1:1. Activation is conduct at $600^{\circ} \mathrm{C}$ for 1 hour, orange peel then washed with bidistiled water, and dried in oven at $150^{\circ} \mathrm{C}$ for 6 hours. Iodine number was used to analysis the results. Adsorption of Remazol Brilliant Blue dyes by orange peel activated carbon conduct at variation contact time and mass activated carbon to find optimum condition. Optimum condition adsorption of Remazol Brilliant Blue dyes by orange peel actvated carbon is reached at 30 minutes contact time with mass activated carbon 1 gram. Activated carbon from orange peel has surface area $529,17 \mathrm{~m} \mathrm{~g} / \mathrm{gr}$ based aqueous iodine adsorption.
\end{abstract}

Keywords: activated carbon, adsorption, iodine number, orange peel, Remazol Brilliant Blue

\section{PENDAHULUAN}

Limbah cair industri merupakan buangan yang dihasilkan dari berbagai proses produksi di industri (Quek dkk., 1998 dalam Kusmiyati dkk., 2012). Limbah cair ini 
mengandung polutan yang menyebabkan air tersebut menjadi berwarna.Perlu adanya pengolahan limbah sebelum dibuang ke lingkungan agar tidak merusak ekosistem badan air dan tidak menjadi racun bagi organisme air.Saat ini, pengolahan limbah dengan teknik adsorpsi dengan menggunakan berbagaimacam adsorben masih merupakan metodeyang paling menguntungkan karenaefektifitas dan kapasitas adsorpsinya yang tinggi serta biaya operasionalnya yang rendah (Syafalni, et al., 2012 dalam Mizwar, 2012).

Beberapa jenis adsorben yang telah digunakan secara komersial adalah zeolit, silica gel, activated alumina, dan karbon aktif yang merupakan jenis adsorben berpori. Karbon aktif merupakan adsorben yang paling banyak digunakan. Hal ini disebabkan karbon aktif memiliki luas permukaan yang lebih tinggi dari adsorben-adsorben yang lain sehingga dapat mengadsorpsi lebih banyak molekul.Namun, biaya karbon aktif yang cukup tinggi membuat karbon aktif digunakan terbatas untuk penanganan limbah cair pada skala industri (Asgher dan Bhatti, 2012).

Beberapa dekade terakhir, berbagai macam karbon aktif dibuat dari berbagai limbah pertanian dan digunakan sebagai adsorben dengan harga yang murah untuk menghilangkan jenis polutan yang berbeda dari limbah cair (Yin dan Wan Daud, 2007dalam Khaled, 2009). Salah satu dari limbah pertanian yang dapat dimanfaatkan sebagai adsorben adalah limbah kulit jeruk keprok.

Proses pembuatan minuman jeruk keprok, akan menyisakan limbah yang sebagian besar adalah kulit jeruk. Kulit jeruk ini hanya akan dibuang begitu saja dengan jumlah banyak, dan pada akhirnya limbah ini akan menimbulkan masalah terhadap lingkungan seperti bau dan polusi pada tanah jika menumpuk dalam jumlahbesar (Ma E., Cervera, 1993). Pada kulit jeruk masih mengandung selulosa yang cukup tinggi, kandungan selulosa ini memiliki potensi untuk dimanfaatkan sebagai karbon aktif dalam menjerap zat warna.

\section{METODE}

Bahan yang digunakan dalam penelitian ini antara lain: Kulit Jeruk, Zat warna Remazol Brilliant Blue, kertas pH, aquades, $\mathrm{H}_{3} \mathrm{PO}_{4}$ p.a (E.Merck), Amilum (E.Merck), $\mathrm{KI}$ (E.Merck), $\mathrm{I}_{2}$ (E.Merck), dan $\mathrm{Na}_{2} \mathrm{~S}_{2} \mathrm{O}_{3} \cdot 5 \mathrm{H}_{2} \mathrm{O}$ (E.Merck). Metode yang dilakukan meliputi preparasi bahan baku, aktivasi kimia, penentuan panjang gelombang maksimum zat warna Remazol Brilliant Blue, adsorpsi zat warna Remazol Brilliant Blue 125 ppm, dan penentuan daya serap iodin.

Pada proses preparasi bahan baku, kulit jeruk dibersihkan, dikeringkan dengan oven pada suhu $120^{\circ} \mathrm{C}$ selama 5 jam. Arang kulit jeruk dihancurkan dengan blender dan di ayak hingga menjadi serbuk. Setelah itu, dilanjutkan dengan aktivasi kimia dimana serbuk arang kulit jeruk yang telah diayak ditambahkan dengan $\mathrm{H}_{3} \mathrm{PO}_{4}$ dengan perbandingan massa arang : massa $\mathrm{H}_{3} \mathrm{PO}_{4}=1: 1$. Sebelum $\mathrm{H}_{3} \mathrm{PO}_{4}$ dicampur dengan arang, $\mathrm{H}_{3} \mathrm{PO}_{4}$ terlebih dahulu dilarutkan dengan aquades hingga $200 \mathrm{~mL}$. Campuran diaduk selama 1 jam kemudian direndam selama 24 jam. Slurry yang terbentuk disimpan dalam desikator semalam, kemudian dipanaskan dalam furnace pada suhu $600^{\circ} \mathrm{C}$ selama $1 \mathrm{jam}$. Arang yang didapat dicuci dengan aquades sampai pH 6 dan dipanaskan dengan oven suhu $150^{\circ} \mathrm{C}$ selama 6 jam.

Selanjutnya menentukan panjang gelombang maksimum larutan zat warna Remazol Brilliant Blue dengan konsentrasi $30 \mathrm{ppm}$ dengan mengukur absorbansinya dengan Spektrofotometer UV-Vis pada panjang gelombang 480-610 $\mathrm{nm}$ sehingga akan 
didapatkan panjang gelombang maksimum. Setelah itu dilakukan penentuan kondisi optimum adsorpsi zat warna Remazol Brilliant Blue 125 ppm untuk menentukan kondisi optimum. Karbon aktif dari kulit jeruk dengan variasi massa 0,$2 ; 0,4 ; 0,6 ; 0,8 ;$ dan 1 gram ditambahkan ke dalam $100 \mathrm{~mL}$ larutan warna Remazol Brilliant Blue dengan konsentrasi 125 ppm. Campuran karbon aktif dan larutan warna Remazol Brilliant Blue diaduk menggunakan magnetic stirer dengan variasi waktu kontak 10, 30, 50, 70, 90, dan 180 menit. Hasilnya disaring dan diukur absorbansinya pada panjang gelombang maksimum.

Karbon aktif yang didapat, dilakukan uji daya serap terhadap larutan iodin. Sampel kering sebanyak 0,5 g dimasukkan ke dalam erlenmeyer, lalu ditambahkan $50 \mathrm{ml}$ larutan $\mathrm{I}_{2} 0,1 \mathrm{~N}$, kemudian dikocok selama 15 menit pada suhu kamar dan selanjutnya disaring. Filtrat sebanyak $10 \mathrm{~mL}$ dititrasi dengan larutan Natrium Tiosulfat $\left(\mathrm{Na}_{2} \mathrm{~S}_{2} \mathrm{O}_{3}\right) 0,1$ $\mathrm{N}$ hingga berwarna kuning muda lalu diberi beberapa tetes larutan amilum $1 \%$ dan titrasi dilanjutkan sampai warna biru tepat hilang. Daya Serap Iodin dapat ditentukan dengan persamaan sebagai berikut (ASTM, 1999).

$$
\text { DSI }=\frac{\left(\mathrm{ml} \text { sampel }-\frac{\mathrm{T} \times \mathrm{C} 1}{\mathrm{C} 2}\right) \times \mathrm{W} \times 5}{\text { gr sampel }}
$$

Dimana :

DSI = Daya Serap Iodin (mg g-1)

$\mathrm{mL}$ sampel $=$ filtrat yang dititrasi $(10 \mathrm{~mL})$

$\mathrm{T}=$ volume titrasi $\mathrm{Na}_{2} \mathrm{~S}_{2} \mathrm{O}_{3}(\mathrm{~mL})$

$\mathrm{C} 1=$ konsentrasi $\mathrm{Na}_{2} \mathrm{~S}_{2} \mathrm{O}_{3}(\mathrm{~N})$

$\mathrm{C} 2=$ konsentrasi $\operatorname{Iodin}(\mathrm{N})$

$\mathrm{W}=$ berat iod $(12.693 \mathrm{mg} \mathrm{mL}-1)$

$5=$ Faktor Pengenceran

\section{HASIL DAN PEMBAHASAN}

\subsection{Preparasi Bahan Baku}

Kulit jeruk keprok dicuci yang telah dibersihkan, dikeringkan untuk menghilangkan kandungan air serta senyawa lain yang mudah menguap (volatile) dengan menggunakan oven pada suhu $120^{\circ} \mathrm{C}$ selama 3 jam. Setelah didapat arang pada proses pengeringan, arang dari kulit jeruk tersebut kemudian dihaluskan hingga menjadi serbuk dengan menggunakan blender dan dilakukan pengayakan menggunakan ayakan yang berukuran sekitar 40 mesh. Pengecilan ukuran akan semakin memperluas area permukaan arang saat proses aktivasi sehingga dapat memperbanyak pori-pori yang terbentuk. Tujuan arang diayak untuk mendapatkan ukuran arang kulit jeruk yang seragam.

\subsection{Aktivasi Kimia}

Hasil dari proses pengeringan biasanya masih memiliki luas permukaan aktif yang kecil karena masih banyak volatil dan tar yang terperangkap dalam karbon sehingga menutupi karbon aktif dan membatasi daya adsorb dari karbon tersebut karena karbon masih berikatan dengan volatil dan atau tar. Sehingga dilakukan proses aktivasi kimia dengan tujuan untuk menghilangkan volatil dan tar yang tersisa sehingga karbon benarbenar bebas dan luas permukaannya pun semakin besar.

Pada aktivasi kimia, aktivator yang digunakan adalah asam phospat $\left(\mathrm{H}_{3} \mathrm{PO}_{4}\right)$. Penggunaan $\mathrm{H}_{3} \mathrm{PO}_{4}$ sebagai aktivator karena $\mathrm{H}_{3} \mathrm{PO}_{4}$ dapat digunakan sebagai bahan pengaktif menggantikan zinc klorida $\left(\mathrm{ZnCl}_{2}\right)$ yang bersifat korosif dan berbahaya karena 
mengeluarkan gas klor, namun $\mathrm{H}_{3} \mathrm{PO}_{4}$ menghasilkan daya serap yang tidak jauh berbeda dan dapat menghasilkan rendemen yang lebih besar (Garcia et al., 2002; Park and Kim, 2003 dalam Pari, 2006).Dalam proses ini, digunakan perbandingan 1:1 antara karbon aktif dan air. $\mathrm{H}_{3} \mathrm{PO}_{4}$ sebanyak 30 gram diencerkan dengan aquades hingga $200 \mathrm{ml}$, kemudian ditambahkan 30 gram arang dari kulit jeruk. Campuran ini diaduk pada suhu ruang selama 1 jam menggunakan pengaduk kaca, kemudian direndam selama 24 jam sampai campuran tersebut menjadi slurry. Setelah itu, slurry dimasukkan ke dalam furnace untuk dipanaskan pada suhu $600^{\circ} \mathrm{C}$ tanpa kehadiran oksigen. Hal ini dikarenakan kehadiran oksigen dapat membakar bahan dasar sehingga akan terjadi banyak hilangnya bahan dasar pada hasil akhir karbon aktif. Aktivator memiliki rentang suhu tertentu dimana aktivatordapat bereaksi dengan karbon sehingga membentuk pori-pori. Jika suhu yang digunakan untuk proses aktivasi tidak berada di rentang suhu tersebut, maka dapat dipastikan bahwa aktivator tidak dapat bereaksi dengan optimum dengan karbon saat proses aktivasi. Aktivasi kimia menggunakan $\mathrm{ZnCl}_{2}$ dan $\mathrm{H}_{3} \mathrm{PO}_{4}$, biasanya dilakukan pada suhu $450^{\circ}-600^{\circ} \mathrm{C}$ (Marsh et al., 2006). Oleh karena itu, pada penelitian ini digunakan suhu aktivasi $600^{\circ} \mathrm{C}$ dengan tujuan aktivasi dapat berjalan optimum.Melalui proses aktivasi ini, arang akan memiliki daya serap yang semakin tinggi. Hal ini disebabkan pada proses aktivasi, kotoran-kotoran yang menutupi pori-pori karbon ikut terlepas (menguap) seiring pertambahan suhu aktivasi.

Setelah aktivasi selesai, dilakukan proses netralisasi pada hasil aktivasi kimia tersebut. Proses ini bertujuan untuk menghilangkan pengotor hasil aktivasi kimia. Proses penetralan dilakukan dengan pencucian sampel secara berulang-ulang menggunakan aquades sampai $\mathrm{pH}$ 6. Setelah penetralan selesai, dilakukan pengeringan sampel pada $\mathrm{T}=150^{\circ} \mathrm{C}$ selama 6 jam hingga sampel kering. Proses pengeringan sampel dilakukan menggunakan oven.

\subsection{Penentuan Panjang Gelombang Maksimum Zat Warna Remazol Brilliant Blue}

Penentuan panjang gelombang maksimum diperoleh dengan mengukur absorbansi zat warna Remazol Brilliant Bluepada panjang gelombang 580 - 610 nm.Panjang gelombang maksimum yang diperoleh adalah $590 \mathrm{~nm}$.

\subsection{Penentuan Waktu Kontak dan Massa Karbon Aktif Optimum}

Waktu kontak merupakan waktu yang dibutuhkan oleh karbon aktif untuk mengadsorpsi zat warna Remazol Brilliant Blue.Hubungan antara adsorpsi zat warna Remazol Brilliant Blue dan waktu kontak dilakukan untuk mengetahui nilai persentase zat warna yang teradsorpsi.Semakin lama waktu kontak antara zat warna Remazol Brilliant Blue dengan karbon aktif maka persentase zat warna yang teradsorpsi akan semakin meningkat. Hal ini sejalan dengan hasil penelitian Isa, et al. (2007) dan Khan dan Chaudhuri (2010) dalam Mizwar (2012) yang menunjukkan bahwa penyisihan warna dengan proses adsorpsi karbon aktif terjadi seiring dengan peningkatan dosis karbon aktif dan lama pengadukan.

Dari Gambar 1 dapat dilihat lebih dari 90\% zat warna yang teradsorpsi pada menit ke 50 untuk karbon aktif dengan massa 0,6 sampai 1 gram dan kemudian kecepatan adsorpsi semakin lambat. Kecepatan adsorpsi pada awal waktu kontak dapat dijelaskan dengan tersedianya muatan positif pada permukaan karbon yang menyebabkan daya tarik elektrostatik pada anion larutan Remazol Brilliant Blue. Kecepatan adsorbsi yang semakin lambat kemungkinan terjadi karena difusi pori yang lambat dari ion zat terlarut ke dalam sebagian besar karbon aktif (Khaled, 2009a). 


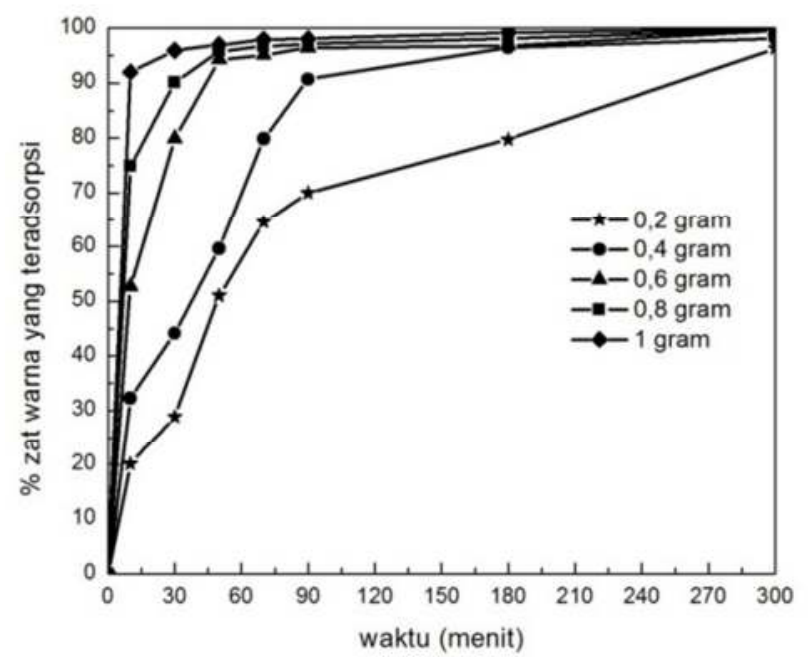

Gambar 1. Grafik Adsorpsi Larutan Remazol Brilliant Blue

Persentase zat warna yang teradsorpsi semakin meningkat dari $79 \%$ sampai 96\% pada menit ke 180 dengan semakin meningkatnya massa karbon aktif dari 0,2 gram hingga 1 gram. Peningkatan adsorpsi zat warna dengan massa karbon aktif dapat dikaitkan dengan peningkatan luas permukaan karbon aktif dan ketersediaan lebih situs adsorpsi. Maka, massa karbon aktif optimum dan waktu kontak adsorpsi optimum untuk larutan Remazol Brilliant Blue adalah 1 gram dan 30 menit.

\subsection{Penentuan Isoterm Adsorpsi}

Adsorpsi biasanya ditulis dengan isoterm yang menunjukkan hubungan antara konsentrasi zat warna yang diserap (adsorbat) dan jumlah yang diserap pada temperatur konstan (Stum dan Morgan, 1995 dalam Rakhmawati, 2007). Dua jenis isoterm adsorpsi yang sering digunakan untuk menentukan isoterm pada proses adsorpsi ini adalah isoterm adsorpsi Langmuir dan Freundlich.

1. Isoterm Langmuir

Penentuan isoterm langmuir dilakukan dengan cara membuat kurva hubungan antara 1/C (1/konsentrasi akhir larutan) dan 1/q (1/daya serap). Kurva isoterm adsorpsi Langmuir ditunjukkan oleh Gambar 2.

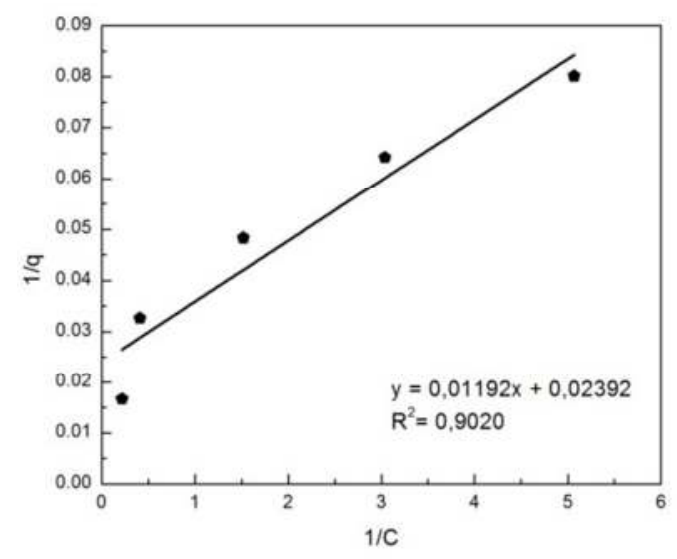

Gambar 2. Grafik Isoterm Adsorpsi Langmuir 
Dari kurva isoterm adsorpsi Langmuir pada Gambar 2 diperoleh persamaan garis lurus $y=0,01192 x+0,02392$ dengan harga $R^{2}=0,9020$.

2. Isoterm Freundlich

Isoterm Freundlich ditentukan dengan cara membuat kurva hubungan $\log \mathrm{C}$ dan $\log$ q. Kurva isoterm adsorpsi Freundlich $\log \mathrm{C}$ versus $\log \mathrm{q}$ disajikan pada Gambar 3

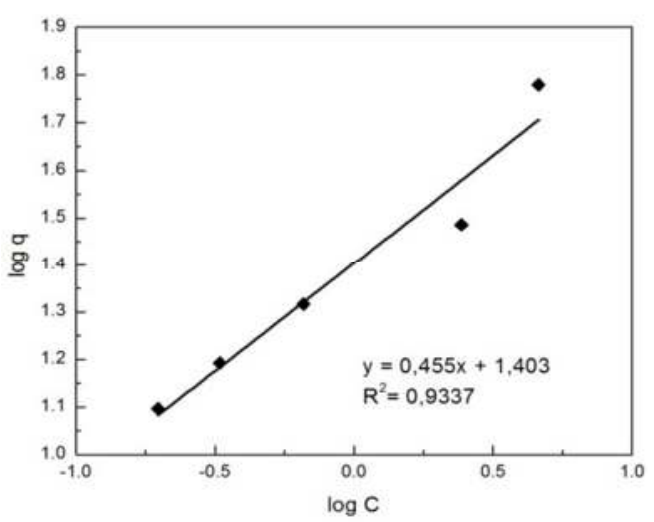

Gambar 3 Grafik Isoterm Adsorpsi Freundlich

Dari kurva isoterm adsorpsi Freundlich diperoleh persamaan garis lurus $\mathrm{y}=0,455 \mathrm{x}+$ 1,403. Harga koefisien regresi linier $\left(\mathrm{R}^{2}\right)$ isoterm Freundlich $(0,9337)$ lebih besar bila dibandingkan dengan isoterm Langmuir $(0,9020)$ sehingga isoterm adsorpsi yang sesuai untuk penjerapan zat warna Remazol Brilliant Blue adalah isoterm Freundlich. Isoterm Freundlich mengasumsikan bahwa permukaan karbon aktif bersifat heterogen, membentuk banyak lapisan, terdapat sisi aktif adsorpsi yang memiliki afinitas tinggi, dan bagian lainnya memiliki afinitas yang rendah (Susanti, 2009).

\subsection{Analisa Bilangan Iodin}

Adsorbsi iod oleh arang aktif dari limbah kulit jeruk dilakukan dengan memasukkan 0,5 gram arang aktif ke dalam oven pada suhu $115^{\circ} \mathrm{C}$ selama 1 jam. Hal ini dilakukan untuk mengaktifkan karbon aktif secara fisik, karena dengan memanaskan pada suhu $115^{\circ} \mathrm{C}$, air yang terkandung dalam arang aktif akan menguap sehingga pori-pori arang aktif lebih terbuka. Setelah dioven karbon aktif didinginkan dalam desikator, kemudian karbon aktif dimasukkan ke dalam erlenmeyer dan ditambahkan $50 \mathrm{ml}$ larutan iod $0,1 \mathrm{~N}$ berfungsi sebagai adsorbatnya yang akan diserap oleh karbon aktif sebagai adsorbennya dan diaduk dengan magnetik stirer selama 15 menit agar proses adsorpsi karbon aktif terhadap larutan iodin berlangsung cepat sehingga iodin mudah teradsorpsi. Proses pengadukan dilakukan dalam erlenmeyer yang ditutupi plastik berwarna hitam. Hal ini bertujuan dihindarkan dari udara terbuka agar iodin tidak mengalami proses oksidasi karena kontak dengan udara luar.

Banyaknya iodin yang teradsorpsi oleh karbon aktif selanjutnya ditentukan sebagai angka iodin yang menyatakan banyaknya iodin yang mampu diadsorpsi oleh karbon aktif $(\mathrm{mg} / \mathrm{g})$. Larutan iodin kemudian disaring, $10 \mathrm{ml}$ filtratnya dititrasi dengan larutan $\mathrm{Na}_{2} \mathrm{~S}_{2} \mathrm{O}_{3} 0,1 \mathrm{~N}$ sampai warna kuning pucat, selanjutnya ditambahkan indikator amilum sampai terbentuk warna biru kemudian dititrasi kembali dengan $\mathrm{Na}_{2} \mathrm{~S}_{2} \mathrm{O}_{3}$ sampai warna biru tepat hilang. Karbon aktif yang mempunyai daya serap yang tinggi terhadap 
iodin berarti memiliki luas permukaan yang lebih besar dan struktur mikro dan mesoporous yang lebih besar (Jankowska, 1991 dalam Miranti, 2012).

Berikut hasil pengujian bilangan iodin yang merepresentasikan luas permukaan pada karbon aktif yang dihasilkan seperti yang ditunjukkan pada Tabel 1 berikut.

Tabel 1 Hasil Pengujian Bilangan Iodin

\begin{tabular}{ccc}
\hline Titrasi & Volume $\mathrm{Na}_{2} \mathrm{~S}_{2} \mathrm{O}_{3}$ & Bilangan Iodin $(\mathrm{mg} / \mathrm{gr})$ \\
\hline 1 & $5,7 \mathrm{ml}$ & 545,67 \\
2 & $5,8 \mathrm{ml}$ & 532,98 \\
3 & $6 \mathrm{ml}$ & 507,6 \\
Rata-rata & $5,83 \mathrm{ml}$ & 529,17 \\
\hline
\end{tabular}

Dari perhitungan rata-rata diatas, karbon aktif memiliki bilangan iodin sebesar $529,17 \mathrm{mg} /$ gr. Menurut Standar Nasional Indonesia (SNI No. 06-3730) kadar iod dalam karbon aktif mencapai nilai minimum $750 \mathrm{mg} / \mathrm{g}$ (Hendra, 2006 dalam Idrus, 2013). Maka, angka iodin yang dihasilkan dalam proses adsorbsi belum memenuhi SNI.

\section{KESIMPULAN}

1. Tahapan karakteristik pembuatan karbon aktif dari kulit jeruk keprok diantaranya preparasi, dehidrasi, aktivasi kimia dengan $\mathrm{H}_{3} \mathrm{PO}_{4}$, netralisasi dengan aquades sampai $\mathrm{pH}$ 6, dan dikeringkan pada suhu $150^{\circ} \mathrm{C}$ selama 6 jam.

2. Karbon aktif dari kulit jeruk keprok mampu menjerap zat warna Remazol Brilliant Blue dengan kondisi optimum pada waktu kontak selama 30 menit dan massa karbon aktif 1 gram.

3. Jenis isoterm Freundlich lebih sesuai pada proses adsorpsi zat warna Remazol Brilliant Blue oleh karbon aktif dari kulit jeruk keprok.

4. Hasil analisis bilangan iodin adalah $529,17 \mathrm{mg} / \mathrm{gr}$, yang menunjukkan luas permukaan karbon aktif.

\section{DAFTAR PUSTAKA}

Asgher M, Bhatti HN, (2012),Evaluation of thermodynamics and Effect of Chemical Treatments on Sorption Potential of Citrus Waste biomass for Removal of Anionic Dyes from Aqueous Solutions. Ecol. Eng., 38, pp. 79-85

ASTM,(1999),Standard Test Method for Determination of Iodine Number of Activated Carbon.American Society for Testing and Material,Philadelpia.

Idrus, Rosita, Boni Pahlanop Lapanporo, Yoga Satria Putra,(2013), Pengaruh Suhu Aktivasi Terhadap Kualitas Karbon Aktif Berbahan Dasar Tempurung Kelapa. Jurnal PRISMA FISIKA, Universitas Tanjungpura Pontianak, I, pp. $50-55$

Khaled, Azza , O. Abdelwahab, A. El-Sikaily, and A. El Nemr,(2009a),Treatment of Artificial Textile Dye Effluent Containing Direct Yellow 12 by Orange Peel Carbon. International Conference on Aquatic Resources: Needs and Benefits NIOF, Alexandria. pp. 210-232 
Kusmiyati, Puspita A.L, Kunthi P,(2012),Pemanfaatan Karbon Aktif Arang Batubara (KAAB) Untuk Menurunkan Kadar Ion Logam Berat $\mathrm{Cu}^{2+}$ Dan $\mathrm{Ag}^{+}$Pada Limbah Cair Industri. Jurnal:Reaktor, 14, pp. 51-60

Ma E., Cervera Q., Mejía Sánchez G. M, (1993),Integrated Utilization of Orange Peel. Bioresource Technology 44, pp. 61-63.

Marsh, Harry Francisco Rodriguez-Reinoso, (2006),Activated Carbon. Publisher: Elsevier Science \& Technology Books.

Miranti, Siti Tias,(2012),Pembuatan Karbon Aktif dari Bambu dengan Metode Aktivasi Terkontrol Menggunakan Activating Agent $\mathrm{H}_{3} \mathrm{PO}_{4}$ dan $\mathrm{KOH}$. Skripsi. Universitas Indonesia.

Mizwar, Andy, (2012),Penyisihan Warna Pada Limbah Cair Industri Sasirangan dengan Adsorpsi Karbon Aktif. Jurnal INFO TEKNIK, 13 (I), pp. 11-16.

Pari, G, D. Hendra dan R.A. Pasaribu, (2006),Pengaruh Lama Waktu Aktivasi Dan Konsentrasi Asam Fosfat Terhadap Mutu Arang Aktif Kulit Kayu Acacia Mangium. Jurnal Penelitian Hasil Hutan, 24 (1), pp. 33-46. Pusat Litbang Hasil Hutan, Bogor.

Rakhmawati, Eka, (2007),Pemanfaatan Kitosan Hasil Deasitelasi Kitin Cangkang Bekicot sebagai Adsorben Zat Warna Remazol Yellow.Skripsi. Universitas Sebelas Maret.

Susanti, Aprilia,(2009), Potensi Kulit Kacang Tanah sebagai Adsorben Zat Warna Reaktif Cibacron Red. Skripsi. Institut Pertanian Bogor. 